\title{
Magnitude and Factors Affecting the Fertility Desire of People Living with HIV Infection in Ethiopia- A Cross Sectional Study
}

Mesoud M Ahmed ${ }^{1}$, AlemayehuBKahsay ${ }^{2}$, GebremeskelMiruts ${ }^{2}$ and KalayouK berhe ${ }^{1 *}$

${ }^{1}$ Department of Nursing, College of Health sciences, Mekelle University, Tigray, North Ethiopia

${ }^{2}$ Department of Public health, College of Health sciences, Mekelle University, Tigray, North Ethiopia

\section{Abstract}

Background: Sub-Saharan Africa remained the most affected region in the global AIDS epidemic which is 22.4 million and whereas in Ethiopia 980000 of people living with HIV. ART enables a return to normal life, including a resumption of sexual activity and a new or renewed desire for children.

Objective: The aim of the study was to assess the magnitude and factors affecting fertility desire among people living with HIV infection in WoreiluWoreda at Worailu health center.

Methods: A facility based cross-sectional study design was used to collect data from 392 HIV positive patients/ clients which is supplemented by qualitative in-depth interview. Study subjects were selected using systematic random sampling. univariate analysis such as percentages, frequency distributions was used to describe the data . bivariate analysis usedto cheack association and finally binary logistic regression model was fitted to examine the effect of the independent variables on the fertility desire.

Result:The study subjects consisted of 206 (52.55\%) females and 186 (47.45\%) males. among the study subjects, $155(39.54 \%)$ respondents had fertility desire.Generally, respondents who were single, widow/widowed and divorced were $0.158(95 \% \mathrm{Cl}=0.035,0.716), 0.042(95 \% \mathrm{Cl}=0.004,0.469)$ and $0.140(95 \% \mathrm{Cl}=0.028,0.714)$ times less likely to desire fertility when compared with those respondents who were marriedrespectively.

Conclusion:This study revealed that a high number of HIV positive men and women desired children. Fertility decisions in peoples living with HIV are not only affected by their HIV status but depends on different predictor factors. Those who desire fertility are having no children or less number of children, married or in relationship and have partners who also desire children. Therefore concerned body should expand PMTCT service in all health centers including private sectors.

Keywords: ART; Fertility desire; HIV positive men; HIV

\section{Introduction}

Human Immune Deficiency Virus (HIV)/Acquired Immune Deficiency Syndrome (AIDS) is the major health, social and political problem in worldwide which has taken a distressing effect in many societies. It ranks fourth among the leading causes of death worldwide and first in Sub-Saharan Africa. Approximately 33.4 million people worldwide were living with HIV in 2010 and 2 million deaths, out of this only about $40 \%$ knows their HIV status and 10 million are waiting for treatment and 5 million people are on treatment. Sub-Saharan Africa remained the most affected region in the global AIDS epidemicwhich is 22.4 million and whereas inEthiopia980000of people living with HIV [1,2].

The majority of new human immunodeficiency virus (HIV) infections that occur in children worldwide occur among children born to HIV positive mothers, who acquire the HIV infection from their mothers.Major strides have been made in recent years in expanding access to antiretroviral therapy (ART) and comprehensive care for HIVinfected men and women in sub-Saharan Africa .For many people living with HIV, ART enables a return to normal life including a resumption of sexual activity and a new or renewed desire for children. This desire is often fueled by the strong societal and traditional values attached to parenthood in sub-Saharan Africa and is further enhanced by the development of increasingly effective antiretroviral regimens to reduce the risk of HIV transmission from an infected mother to her newborn or breastfeeding child.The success of highly active antiretroviral therapy (HAART) in reducing morbidity and mortality from HIV/ AIDS has been widely documented. Consequently, many HIV-infected persons are now living longer, healthier, and more productive lives. The infection rate among pregnant women in Sub-Saharan Africa is also alarmingly high, where $90 \%$ of global new child infections through mother-to-child transmission (MTCT) [3-6]

Since access to antiretroviral therapy has improved quality of life and survival for HIV infected people, many will contemplate child bearing. Identification of contextual determinants of decision to have children among HIV positive couples is useful for designing of policies. African woman are being infected at an earlier age than men, and the gap in HIV prevalence between them continue to grow. At the beginning of the epidemic in sub-Saharan Africa, women living with HIV were vastly at number than men. But today, there are on average 13 infected women for every 10 infected men in 2010. The majority of all new HIV infections are occurring among women of childbearing age and recent evidence shows that pregnant women may be at a higher risk of HIV infection than lactating women or non-pregnant, non-breastfeeding women. While antiretroviral treatment (ART) has improved the health

${ }^{*}$ Corresponding author: Kalayou K Berhe, Mekelle University, College of Health Sciences,Department ofNursing, PO.Box 1871, Tigray region, North Ethiopia, Tel: 251912117719; E-mail: kalushaibex@yahoo.com

Received April 21, 2014; Accepted August 26, 2014; Published September 06 2014

Citation: Ahmed MM, Kahsay AB, Miruts G, Berhe K (2014) Magnitude and Factors Affecting the Fertility Desire of People Living with HIV Infection in Ethiopia, A Cross Sectional Study. J AIDS Clin Res 5: 343. doi:10.4172/2155-6113.1000343

Copyright: (c) 2014 Ahmed MM, et al. This is an open-access article distributed under the terms of the Creative Commons Attribution License, which permits unrestricted use, distribution, and reproduction in any medium, provided the original author and source are credited. 
status of people living with HIV, new challenges to their sexual and reproductive health (SRH) needs and their ability to prevent secondary HIV infections have risen..The increasing feminization of the global HIV epidemic is widely recognized this is because in 1985 almost $35 \%$ ofthe totalHIV infected population were women. The majority of women living with HIV are in their reproductive age, highlighting the critical need to address issues surrounding reproductive and sexual rights, including in relation to childbearing and pregnancy. Acrosssectional study conducted in South Africa one-third of HIV-infected individuals receiving ART would like to become pregnant in the future and high prevalence of fertility desires among men [7-9].

As EFY(Ethiopian Fisical Year) 2003 Annual report shows a total of 8,365 HIV-positive mothers received ART(Anti Retro Viraltherapy) treatment which contributing to $9.3 \%$ of those eligible $(90,311)$. Despite the increase in $\mathrm{ANC}$ (Antenatal care) coverage observed in the past years, PMTCT coverage is still low (9.3\%) and there are 1,150 ever enrolled HIV infected individuals at Woreilu Health Center in February $2010[10,11]$.

\section{Methods and Materials}

\section{Study design, study area and period}

A Facility based cross sectional study design was employed and data was collected using iterviwer administered structure quesionnaire (quantitative method) and further supplemented by in depth interview (qualitative method). The study was conducted in Woreilu Health Center found in town of Woreilu Woreda, Amhara Region from January 2012 to May 2012. Based on the 2007 Census conducted by the Central Statistical Agency (CSA) of Ethiopia South Wollo Zone has a total population of $2,518,862$. It has 3 government hospitals, 132 Health centers and 469 Health posts. Geographically, the Woreda is located $500 \mathrm{~km}$ away from Addis Ababa. Woreilu is the district city of Woreilu Administrative Woreda., and it has 4 Health centers and 20 Health Posts. Among all health centers woreilu health centers is the only which provide ART service in the woreda

\section{Source population}

The source population was all HIV positive individuals who visited ART clinic of the health center their age were 18 years old or above for men and reproductive age group (15-49 years old) for women and appeared during the study period.

\section{Sample size determination}

Quantitative method: The sample size was determined using single population proportion determination formula. A previous study conducted in South Wollo [6] revealed that the proportion of fertility desire of married men and women living with HIV was18.3\% with expected margin of error(d) $4 \%$ just to maximize my sample size and improve the precision of my study given the cost and time, $95 \%$ confidence interval

$$
\left(\mathrm{Z}_{1 / 2}\right) \mathrm{n}=\underline{\left(\mathrm{Z} \alpha_{12}\right.} \underline{2}^{2} \underline{\mathrm{P}(1-\mathrm{P})} / \mathrm{d}^{2} \mathrm{Z}=1.96
$$

( $95 \%$ confidence interval), $\mathrm{d}=0.04$ margin of error, $\mathrm{P}=0.18$ then the sample size was $=354.4$, Non-response rate $10 \%=35.44+354.4$, Total $=392$ participants

Qualitative method: For qualitative method the number of people planed to be interviewed was 12 (Six females and Six males). But the selection continued until the point of redundancy and eight respondents, equal number of males and females were interviewed by the data collectors.

Sampling procedure: For quantitative study, particapants were selected using systematic random sampling technique from regestration book and convinnet sampling methed was used to select particpants for qualitaitive study.

Data collection procedure: Interviwer administered Structured questionnaire was applied as a quantitative data collection instrument. Three Diploma nurses as data collectorand one BSC nurse as supervisor from Kelalla Woreda were hired to collect data. To maintain data quality the questioner was preteted on nearby Degollo Health center on $5 \%$ of the client and extensive supervision was made daily by the supervisor during data collection. In addition, an open ended semi-structured interview guide was prepared and used for the qualitative study. Each interview was carried out by data collectors and field notes was taken.

\section{Data management and analysis}

Quantitative data analysis: Quantitative data was entered using SPSS version 16 and exported to STATA version 11 for analysis. Exploratory data analysis (EDA) was made before computing any statistical analysis. Consequently, outliers, Multi-collinearity and Independence of observationswere checked up. The univariate analysis such as percentages, ratios, frequency distributions and appropriate graphic presentations, summary tables and charts was used to describe the data used in the study. In the bivariate analysis $\chi^{2}$ tests of association was used using $p$-value 0.20 . Based on the results of bivariate analysis, i.e. using variables found significant in the bivariate case binary logistic regression model was fitted to examine the effect of the independent variables on the fertility desire. The presence of potential confounder and interactions between fertility desire and other exposure variables was assessed using stratification and multivariate techniques.Finally, variables which was show significant association in the bivariate analysis with $\mathrm{p}$ value $<0.2$ was included in the final logistic regression model and $95 \%$ confidence interval for all odds ratio was used.

Qualitative data analysis: The qualitative data that was found from in-depth interview was analyzed by applying thematic analysis approach. Once the data is collected, it was transcribed and pattern of common ideas was listed. Then, related data to the classified patterns was identified and combined in to sub themes.

Ethical consideration:Ethical approval was gained from the ethical review committee of the Mekelle University, college of Health science and Letter of permission was obtained from Woreilu Woreda Health office before conducting the study. Participants who included in the study were informed about the aim and duration of study, then oral consent was obtained from each participants.

\section{Results}

\section{Quantitative result}

Socio demographic characterstics of respondent: A total of 392 patients were enrolled and completed the baseline interview during the study period. Among the total study subjects 206 (52.55\%) were females. Majority of respondents $43.37 \%$ were aged between $25-34$ years. Marital wise, the majority were married contributing about 182 (46.43\%). The predominant religion was Muslim 208 (53.06\%).

Regarding their educational status, more than one fourth of the study subjects $129(32.91 \%)$ were illiterate Of all interviewed patients, $212(54.16 \%)$ of them were not using any family planning method. Largest portion 326 (83.16\%) of respondents knew about MTCT out 


\begin{tabular}{|c|c|c|c|}
\hline Characteristics & $\mathrm{N}(\%)$ & Characteristics & $\mathbf{N}(\%)$ \\
\hline Sex & & Fertility Desire & \\
\hline Male & $186(47.45)$ & Yes & $155(39.54)$ \\
\hline Female & $206(52.55)$ & No & $237(60.46)$ \\
\hline Categorized Age (Years) & & Partners Fertility desire & \\
\hline $15-24$ & $53(13.52)$ & Yes & 116 (29.59) \\
\hline $25-34$ & $170(43.37)$ & No & $74(18.88)$ \\
\hline $35-44$ & $135(34.49)$ & Do not know & $48(12.25)$ \\
\hline$\geq 44$ & $34(8.67)$ & Don't have partner & 154 (39.29) \\
\hline Religion & & Number of children alive & \\
\hline Muslim & 208 (53.06) & $0-2$ & $42(10.71)$ \\
\hline Orthodox & $164(41.84)$ & $3-5$ & $315(80.36)$ \\
\hline Protestant & $20(5.10)$ & $\geq 6$ & $35(8.93)$ \\
\hline Educational Status & & Number of Children desired by respondents' partener & \\
\hline Can read and write & $81(20.66)$ & $\leq 2$ & $193(49.23)$ \\
\hline Cannot read and write & $129(32.91)$ & $>2$ & $199(50.77)$ \\
\hline Primary & $109(27.82)$ & Use of FP & \\
\hline Secondary & $57(14.54)$ & Yes & 177 (45.15) \\
\hline Tertiary or university & $14(3.57)$ & No & 212 (54.16) \\
\hline Occupation & & No response & $3(0.77)$ \\
\hline Farmer & $171(43.6)$ & Know MTCT & \\
\hline House wife & $67(17.1)$ & Yes & $326(83.16)$ \\
\hline Merchant & $58(14.8)$ & No & $36(9.18)$ \\
\hline Gov't employee & $31(7.9)$ & Do not know & $30(8.65)$ \\
\hline Day labor & $50(12.8)$ & Medication to PMTCT & \\
\hline Student & $10(2.6)$ & Yes & 281 (71.68) \\
\hline No job & $3(.8)$ & No & $43(10.97)$ \\
\hline Marital status & & Do not know & $68(17.34)$ \\
\hline Married & $182(46.43)$ & Medication provided for PMTCT actually reduce the transmission & \\
\hline Single & $21(5.36)$ & Yes & $232(59.18)$ \\
\hline Widow/widowed & $71(18.11)$ & No & \\
\hline Divorced & $85(21.68)$ & Do not know & $110(28.06)$ \\
\hline Non married partner* & $33(8.42)$ & No response & $2(0.51)$ \\
\hline
\end{tabular}

*None married partener means in this research those who are capul and living together but not married official

Table 1: Socio demographic and other fertility desire related characteristics of subjects.

of these $281(71.68 \%)$ of them knew the availability of medication used to prevent mother to child HIV transmission.It is claimed that, health professionals and Public media were identified as major sources of information about mother to child transmission and prevention accounting $212(54.10 \%)$ and $12(3.06 \%)$ respectively. More than half 232 (59.18\%) of them believed that, the medication for PMTCT can actually reduce the transmission (Table 1).

Fertility desirewith socio-demographic variables: As depicted in Table 2, fertility desire was disaggregated based on the different sociodemographic characteristics. Generally, as described above, 155 (39.54) respondents have desire to have children while the rest have no desire. Of all study participants, 87 (46.77\%) of male and 68 (33.01\%) of female respondents had fertilitydesire.

Fertility desire with other characteristics of study subject: Among those whose partners wish to have children, 85 (73.28) of them have fertility desire. As expected, more than half 102(57.63\%) of family planning users don't want to have child. Conversely, out of those respondents who were not using family planning methods, large proportion of them 133 (62.74\%) had no fertility desire.

Regarding ART enrollment, majority, $60 \%$ of respondents who have started receiving ART were found to have no fertility desire. The study demonstrated that, as the time spent after the respondent knew his/her
HIV status gets increased, the fertility desire showed little increment. Similarly, as the ART treatment duration was greater than a year, the fertility desire increased from $32.9 \%$ to $41.2 \%$.Variation was observed in the fertility desire of partners who have HIV test and who don't have HIV test, contributing $48 \%$ and $40 \%$ respectively,while there was no difference in the fertility desire of partners' with positive or negative HIV test result. (Table 3 ).

Determinants of fertility desire (Bivariate Analysis): Among the socio-demographic characteristics of respondents, sex, age and marital relationship were largely found to be associated with fertility desire even after adjusting for other selected socio-demographic variables.

Multiple logistic regression analysis: Multiple logistic regression analysisidentify; marital status, number of alive children and partners fertility desir as predictor variables of fertility desir.

The odds of fertility desire for respondents' who were single, widow/ widowed and divorced were 0.158 (95\% CI=0.035, $0.716 \mathrm{p}$-values $<0.017), 0.042(95 \% \mathrm{CI}=0.004,0.469 \mathrm{p}$-values $<0.010)$ and $0.140(95 \%$ $\mathrm{CI}=0.028,0.714 \mathrm{p}$-values $<0.018)$ respectively times less likely to desire fertility when compared with those respondents who were married. While those respondents who had partner but not married were $1.933(95 \% \mathrm{CI}=0.537,6.949)$ times more likely to desire fertility when compared with married respondents. Comparing fertility desire of 


\begin{tabular}{|c|c|c|c|c|}
\hline \multirow{3}{*}{ Characteristics } & \multicolumn{4}{|c|}{ Fertility Desire } \\
\hline & \multicolumn{2}{|c|}{ Yes } & \multicolumn{2}{|c|}{ No } \\
\hline & Count & N\% & Count & $\mathbf{N} \%$ \\
\hline \multicolumn{5}{|l|}{$\operatorname{Sex}(n=155)$} \\
\hline Male & 87 & 46.77 & 99 & 53 \\
\hline Female & 68 & 33.01 & 138 & 67 \\
\hline \multicolumn{5}{|l|}{ Religion ( $n=155$ ) } \\
\hline Muslim & 91 & 35.98 & 117 & 56 \\
\hline Orthodox & 59 & 25 & 105 & 64 \\
\hline Protestant & 5 & 35.8 & 15 & 75 \\
\hline \multicolumn{5}{|l|}{ Educational Status ( $n=155)$} \\
\hline Attend basic education & 29 & 46.79 & 52 & 64 \\
\hline Illitrate & 39 & 49.12 & 90 & 70 \\
\hline Primary & 51 & 42.86 & 58 & 53 \\
\hline Secondary & 28 & 43.41 & 29 & 51 \\
\hline tertiary or university & 6 & 28.57 & 8 & 57 \\
\hline \multicolumn{5}{|l|}{ Marital Status (n=155) } \\
\hline Married & 79 & 43.41 & 103 & 57 \\
\hline Single & 6 & 28.57 & 15 & 71 \\
\hline Widow/widowed & 21 & 29.58 & 50 & 70 \\
\hline Divorced & 24 & 28.24 & 61 & 72 \\
\hline Non married partner & 25 & 75.76 & 8 & 24 \\
\hline \multicolumn{5}{|l|}{ Occupation (n=155) } \\
\hline Farmer & 58 & 42 & 113 & 66.1 \\
\hline House wife & 20 & 100 & 47 & 70.2 \\
\hline Merchant & 31 & 33.3 & 27 & 46.6 \\
\hline Gov'temployee & 12 & 75.6 & 19 & 61.3 \\
\hline Day labor & 21 & 38.2 & 29 & 58 \\
\hline Student & 10 & 42.9 & 0 & 0 \\
\hline No job & 1 & 36.5 & 2 & 66.7 \\
\hline \multicolumn{5}{|l|}{ Age $(n=155)$} \\
\hline $15-24$ & 29 & 54.7 & 24 & 45.3 \\
\hline $25-34$ & 68 & 40 & 102 & 60 \\
\hline $35-44$ & 49 & 36.3 & 86 & 63.7 \\
\hline$\geq 45$ & 9 & 26.5 & 25 & 73.5 \\
\hline \multicolumn{5}{|c|}{ Number of alive children ( $n=155$ ) } \\
\hline $0-2$ & 32 & 76.2 & 10 & 24 \\
\hline $3-5$ & 115 & 36.5 & 200 & 63 \\
\hline$\geq 6$ & 8 & 22.9 & 27 & 77 \\
\hline
\end{tabular}

* $\mathrm{n}=155$ means total number of respondents who had fertility desire

Table 2: Distribution of fertility desires according to different socio-demographic indices of respondents.

respondents' partner fertility desire, the odds was 0.059 (95\% CI $=0.026$, $0.134)$ for respondents did not have desire, 0.111 (95\% CI=0.044, 0.280) for those who did not know their partners' desire and $0.430(95 \%$ $\mathrm{CI}=0.092,2.007)$ for those who had not married partner. Respondents having 3-5 and $\geq 6$ alive children were 0.153 (95\% CI=0.045, 0.518) and $0.121(95 \% \mathrm{CI}=0.0243,0.597)$ respectively times less likely fertility desire than those respondents having alive children zero to two.

\section{Qualitative result}

Eight respondents, equal number of male and female, participated in the interview. The respondent's age ranges from 17-42 years. Respondent's educational status varied from cannot read and write to diploma in secretarial science. Out of Eight respondents three were farmer, one student, two merchant and two house wife. Five respondents were Muslim and the rest three were orthodox. Three out of Eight had

children. Six of them start ART and the rest did not and all of them use family planning after they diagnosis.

\section{Desired fertility}

Respondents' reasons for fertility desire were asserted. Out of eight respondents, 2 females and 2 males, total of four respondents reported child desire. Most expressed were to have at least one or two children, availability of ARV treatment and unchanged fertility desire because of HIV/AIDS.

\section{A 27 years old woman with no children express}

"I am positive and I did not have children I need at least one child.I have started the treatment and my health condition is getting improved.I am working like my colleagues and earn adequate income by preparing local katikala [Alchool]. Thus we discussed with my husband and decided to have children in the next year and we stopped using FP."

39 years old man with one child.

"I am farmer now I have only one child my wife was died and I got married another wife, she has not child she loves kid more than me, we want to have three children one female and two males and my health condition improved even I do not fell any think bad I work equally with my friends, I want to show to my neighbors that HIV positive person can do anything like anybody."

\section{7 years man with two daughter}

"I am very eager to have child because I want son who will support me in different activities and he will shield for the two daughters. My husband also wants because of we have no son before.I know that the

\begin{tabular}{|c|c|c|c|c|}
\hline \multirow{3}{*}{ Characteristics } & \multicolumn{4}{|c|}{ Fertility desire } \\
\hline & \multicolumn{2}{|c|}{ Yes } & \multicolumn{2}{|c|}{ No } \\
\hline & Count & $\mathbf{N} \%$ & Count & $\mathbf{N} \%$ \\
\hline \multicolumn{5}{|c|}{ Husband/wife/partner fertility desire } \\
\hline Yes & 85 & 73.28 & 31 & 26.72 \\
\hline No & 12 & 16.22 & 62 & 83.78 \\
\hline Do not know & 13 & 27.08 & 35 & 72.92 \\
\hline Don't have partner & 45 & 29.22 & 109 & 70.78 \\
\hline \multicolumn{5}{|l|}{ Use of family planning } \\
\hline Yes & 75 & 42.37 & 102 & 57.63 \\
\hline No & 79 & 37.26 & 133 & 62.74 \\
\hline \multicolumn{5}{|l|}{ Start Receiving ARV treatment } \\
\hline Yes & 126 & 40 & 189 & 60 \\
\hline No & 29 & 37.66 & 48 & 62.34 \\
\hline \multicolumn{5}{|l|}{ HIV diagnosis duration } \\
\hline$\leq 12$ & 48 & 35.3 & 88 & 65 \\
\hline$>12$ & 107 & 41.8 & 149 & 58 \\
\hline \multicolumn{5}{|l|}{ Treatment duration } \\
\hline$\leq 6$ & 26 & 32.9 & 53 & 67 \\
\hline$>6$ & 129 & 41.2 & 184 & 59 \\
\hline \multicolumn{5}{|c|}{ Husband/wife/partner tested for HIV } \\
\hline Yes & 95 & 48 & 103 & 52 \\
\hline No & 12 & 40 & 18 & 60 \\
\hline No husband/wife/partner & 47 & 31.3 & 103 & 69 \\
\hline \multicolumn{5}{|c|}{ Husband/wife partner HIV test result ( $n=107)$} \\
\hline Negative & 25 & 47.2 & 28 & 53 \\
\hline Positive & 70 & 47 & 79 & 53 \\
\hline
\end{tabular}

Table 3: Distribution of respondents' partner HIV status and Treatment duration by fertility desire. 
Citation: Ahmed MM, Kahsay AB, Miruts G, Berhe K (2014) Magnitude and Factors Affecting the Fertility Desire of People Living with HIV Infection in Ethiopia, A Cross Sectional Study. J AIDS Clin Res 5: 343. doi:10.4172/2155-6113.1000343

Page 5 of 8

\begin{tabular}{|c|c|c|c|c|}
\hline \multirow[t]{2}{*}{ Independent Variables } & \multicolumn{2}{|c|}{ Frequency } & \multirow[t]{2}{*}{ OR $(95 \% \mathrm{Cl})$} & \multirow[t]{2}{*}{$p$ value } \\
\hline & Yes & No & & \\
\hline \multicolumn{5}{|l|}{ Sex } \\
\hline Male & 87 & 99 & 1 & \multirow[t]{2}{*}{0.005} \\
\hline Female & 68 & 138 & $0.560(0.372,0.844)^{*}$ & \\
\hline \multicolumn{5}{|l|}{ Age Category } \\
\hline $15-24$ & 29 & 24 & 1 & \multirow[t]{4}{*}{0.043} \\
\hline $25-34$ & 68 & 102 & $0.552(0.296,1.027)$ & \\
\hline $35-44$ & 49 & 86 & $0.471(0.247,0.898)^{\star}$ & \\
\hline$\geq 45$ & 9 & 25 & $0.298(0.117,0.758)^{*}$ & \\
\hline \multicolumn{5}{|l|}{ Religion } \\
\hline Muslim & 91 & 117 & 1 & \\
\hline Orthodox & 59 & 105 & $0.722(0.475,1.100)$ & 0.117 \\
\hline Protestant & 5 & 15 & $0.429(0.150,1.223)$ & \\
\hline \multicolumn{5}{|l|}{ Educational Status } \\
\hline Attend basic education & 29 & 103 & 1 & \\
\hline Illitrate & 39 & 15 & $0.777(0.431,1.401)$ & \\
\hline Elementary & 51 & 50 & $1.576(0.874,2.843)$ & 0.043 \\
\hline Secondary & 28 & 61 & $1.731(0.868,3.451)$ & \\
\hline Tertiary & 6 & 8 & $1.344(0.425,4.255)$ & \\
\hline \multicolumn{5}{|l|}{ Marital relationship } \\
\hline Married & 79 & 103 & 1 & \\
\hline Single & 6 & 15 & $0.521(0.194,1.405)$ & \\
\hline Widow/widowed & 21 & 50 & $0.547(0.304,0.986)^{\star}$ & 0.0000 \\
\hline Divorced & 24 & 61 & $0.512(0.294,0.894)^{*}$ & \\
\hline Non-married partners & 25 & 8 & $4.074(1.744,9.517)^{*}$ & \\
\hline \multicolumn{5}{|l|}{ Number of children alive } \\
\hline $0-2$ & 32 & 10 & 1 & \multirow[t]{3}{*}{0.0000} \\
\hline $3-5$ & 115 & 200 & $0.178(0.085,0.379)^{*}$ & \\
\hline$\geq 6$ & 8 & 27 & $0.093(.032,0.268)^{\star}$ & \\
\hline \multicolumn{5}{|l|}{ Partners fertility desire } \\
\hline Yes & 85 & 31 & 1 & \\
\hline No & 12 & 62 & $0.071(0.034,0.148)^{*}$ & 0.0000 \\
\hline \multicolumn{5}{|c|}{ Use of Family Planning Method } \\
\hline Yes & 75 & 102 & 1 & \multirow[t]{2}{*}{0.577} \\
\hline No & 79 & 133 & $0.807(0.537,1.215)$ & \\
\hline \multicolumn{5}{|l|}{ knowledge of MTCT } \\
\hline Yes & 137 & 189 & 1 & \\
\hline No & 15 & 21 & $0.985(0.490,1.980)$ & 0.0009 \\
\hline \multicolumn{5}{|c|}{ Knowledge on the PMTCT medication } \\
\hline Yes & 123 & 158 & 1 & \\
\hline No & 20 & 23 & $1.117(0.587,2.127)$ & -0.0001 \\
\hline \multicolumn{5}{|c|}{$\begin{array}{l}\text { Belief on PMTCT medication to reduce } \\
\text { transmission }\end{array}$} \\
\hline Yes & 103 & 129 & 1 & \multirow[t]{2}{*}{0.004} \\
\hline No & 21 & 27 & $0.974(0.520,1.8222)$ & \\
\hline Start Receiving ARV & & & & \\
\hline Yes & 126 & 189 & 1 & 0.706 \\
\hline No & 29 & 48 & $0.906(0.543,1.514)$ & \\
\hline Husband /wife/ partner tes & & & & \\
\hline Yes & 95 & 103 & 1 & 0.0005 \\
\hline No & 12 & 18 & $0.724(0.331,1.580)$ & \\
\hline Husband /wife/ partner tes & & & & \\
\hline Negative & 25 & 28 & 1 & 0.0057 \\
\hline Positive & 70 & 79 & $0.992(0.530,1.856)$ & \\
\hline
\end{tabular}




\begin{tabular}{|c|c|c|c|c|}
\hline Duration of HIV Diagnosis & & & & \\
\hline$\leq 12$ & 48 & 88 & 1 & 0.2085 \\
\hline$>12$ & 107 & 149 & $1.37(0.856,2.025)$ & \\
\hline Duration of ART Treatment & & & & \\
\hline$\leq 6$ & 26 & 53 & 1 & 0.174 \\
\hline$>6$ & 129 & 184 & $1.43(0.849,2.405)$ & \\
\hline
\end{tabular}

Table 4: Bivariate analysis for associations between independent variables and fertility desire $(n=392)$.

\begin{tabular}{|c|c|c|c|c|}
\hline \multirow{2}{*}{ Variables } & \multicolumn{2}{|c|}{ Frequency } & \multirow{2}{*}{ Crude OR $[95 \% \mathrm{CI}]$} & \multirow{2}{*}{ Adjusted OR $[95 \% \mathrm{Cl}]$} \\
\hline & Yes & No & & \\
\hline \multicolumn{5}{|l|}{ Marital Status } \\
\hline Married & 79 & 103 & 1 & 1 \\
\hline Single & 6 & 15 & $0.521(0.194,1.405)$ & $0.158(0.035,0.716)^{*}$ \\
\hline Widow/widowed & 21 & 50 & $0.547(.304,0.986)$ & $0.042(0.004,0.469)^{*}$ \\
\hline Divorced & 24 & 61 & $0.512(0.294,0.894)$ & $0.140(0.028,0.714)^{*}$ \\
\hline Non married partner** & 25 & 8 & $4.074(1.744,9.517)$ & $1.933(0.537,6.949)$ \\
\hline \multicolumn{5}{|l|}{ Number of Live children } \\
\hline $0-2$ & 32 & 10 & 1 & 1 \\
\hline $3-5$ & 115 & 200 & $0.178(0.085,0.379)$ & $0.153(0.045,0.518)^{*}$ \\
\hline$\geq 6$ & 8 & 27 & $0 . .093(.032,0.268)$ & $0.121(0.0243,0.597)^{*}$ \\
\hline \multicolumn{5}{|l|}{ Partners' fertility desire } \\
\hline Yes & 85 & 31 & 1 & 1 \\
\hline No & 12 & 62 & $0.071(0.034,0.148)$ & $0.059(0.026,0.134)^{*}$ \\
\hline Do not know & 13 & 35 & $0.135(0.064,0.289)$ & $0.111(0.044,0.280)^{*}$ \\
\hline Do not have partner & 45 & 109 & $0.151(0.089,0.258)$ & $0.430(0.092,2.007)$ \\
\hline
\end{tabular}

* Significant association ( $p \leq 0.05)$

${ }^{* *}$ None married partener means in this research those who are capul and living together but not married officially

Table 5: Results of Multiple logistic regressions Analysis ( $n=392)$.

virus can be transmitted from mother to child. But I have heard that there is a mediation to prevent its transmission from mother to child. This is the reason why I planned to have a child? And the medication can be reduced by taking ART during pregnancy and seeing the possible options of relevant care, it is possible to curtail its transmission."

32 years old Woman with no children

"Since I love kid and they are my honor, even children are very significant in marriage. The reason why I want child is, my health condition is improved, to substitute myself, to get supporter and in general child is very important in life. My husband also want child. Even though I know the presence of HIV/AIDS with me, it is not changed my desire to get a child not only my desire is avail, but also the number of children which I were dream, is not changed. I want to get four children. The transmission of HIV/AIDS from mother to child is real. Through pregnancy, during delivery in blood contact and breast feeding are some factor for the transmission of HIV/AIDS from mother to child.I know the presence of medication for HIV/AIDS for prevent its transmission from mother to child. I got this know how from health centre, from health extension workers and from mass Medias."

\section{Did not want to have a child}

Four out of Eight respondents explicitly reported not desiring children. Out of those who do not desire children 2 were females and 2 males. Many of respondents who did not want to have a child considered risk of vertical transmission when making decisions about child bearing.

A 25 years old woman with three children expressed
"I do not want to have additional child it is not important. Because I am living with HIV/AIDS I am afraid to have a child, I might die due to the virus before I growth up my child. Even if I have a child with HIV/ AIDS, why he/she suffers due to my problem? There for, I decided not to have a child. While, I know there is medication to prevent mother to child transmission, i.e. by taking care, by taking prophylaxis in proper way. But I do not think it reduces the transmission."

30 years old woman with one son

"For me it is not necessary to born child. Because, I am living with HIV/AIDS, so, I fear if I intend to have child, it may be born with HIV/ AIDS, after my husband died, I did not have married and HIV/AIDS bring so many challenges in my life. Firstly, I missed my couple. In addition to this, after I deliver one child, it passed away. Lastly, I fear always if I may die, they will be alone and I know the transmission of HIV/AIDS from mother to child; even by myself I experienced it. Now, I recognized well, it is possible to prevent the transmission of the virus from mother to child. Health professionals also help me to understand well. As a result of the prophylaxis has been taken, it decreases the gate of transmission. But surely it is not possible to get fully HIV/AIDS free child."

\section{2 years old man with two children}

"I do not want to have additional child. Because, the income which I have is insufficient to lead my children, and once I divorced my wife, I did not marry other wife as I believe that HIV/AIDS affects the health of the child. Generally, being HIV positive has negative impact on my child desire. Before the virus infection, the number of children which I want to get was four. But I restricted to two children only now. I know HIV/AIDS can be transmitted from mother to child. Of course there is 
medication to prevent the transmission. This is practically I have seen from my neighbors."

\section{A 23 years old man with no children expressed}

"I knew I'm positive and my couple is too, I'm quite sure the baby's going to be positive from his mother. The medication, that is said to be available to reduce the chance of transmission, in capable to eliminate and to reduce because, I have practiced that those who use the prophylaxis but their children were infected with the virus. So, how can it be possible to protect the child from getting infected? In addition, my wife is not in good health thus pregnancy will further compromise her health since she carry and feed the fetus for nine months so, we have discussed and agreed not have child, even we have negative opinion on those who wants child being infected with the virus."

\section{Discussion}

To our knowledge, this is the first research in WoreiluWoreda to document the fertility desire of people living with HIV/AIDS in a quantified way. As shown in the result section, this study assesses magnitude of fertility desire among people living with HIV infection and identifies predictor variables of fertility desire for people living with HIV infectioninWoreiluWoreda.

The chi-square statistic from -2 log-likelihoods shows that the model fitted well the data. But the value of pseudo R-square 0.35 was small which indicates there are the proportion of variation explained by explanatory variables in the model is not adequate. This indicates there are other variables which are not included in the study that well explain the variation in fertility desire.

From the total study subjects, 155 (39.54\%) respondents have fertility desire. Likewise, a study done in Addis Ababa revealed out of 414 study subject 165 (39.9\%) had desire to have children in the future [1]. In addition another comparable result was found in a crosssectional study done in Addis Ababa, which showed thatover all 40.2\% of HIV positive individuals receiving care in Addis Ababa desired to have children [12]. On the other hand, the proportion of this study population who desire children was higher than those reported in studies from Amhara region South wollo which is a facility based crosssectional study [6] and conversely a study done in Canada, revealed that $69 \%$ of the respondents would like to give birth in the future $[13,14]$. This discrepancy may be explained by lack of knowledge about PMTCT in South Wollo while the respondents in Canada may be more aware about PMTCT and may have improved health status as compared to the study subjects considered in this study.

The finding showed that, $87(46.77 \%)$ of male respondents and $68(33.01 \%)$ of female respondents had fertility desire. Furthermore, sex was significantly associated with fertility desire in that female respondents were found to be less likely to have fertility in the future as compared with male. However, a study done in northern Nigeria shows that of all 167 (65.5\%) females and 52(61.2\%) males expressed a desire to have more children [9]. This difference may be due to women in Nigeria may be financially strong as well as their literacy might be better than women in our country.

Different factors may influence the fertility desire of individuals. Though, the quantitative study doesn't compare fertility desire among PLHIV and clients without HIV, in the qualitative result opposite ideas were raised regarding the effect of HIV infection on the need to have child. Some of them claimed that being HIV positive has negative effect on the fertility desire of individuals due to fear of transmission to the child, lack of knowledge of PMTCT and considering pregnancy as risk condition for individuals live with HIV while others explained that as ART improves our health condition and it also prevents mother to child transmission, we wanted to have children.

Among others, age and marital status were found to be significantly associated with fertility desire of individuals. The finding showed that the fertility desire of respondents with age category greater than 35 was significantly lower as compared to those respondents younger than 35 years with $p$-value $<0.05$. In addition, widowed and divorcedrespondents have significantly lower fertility desire as compared to other categories of marital relationship while the fertility desire of respondents who have non married partners were found to be four times more higher when compared with married patients. This finding is also supported by the qualitative finding as some widowed respondents claimed that, as their wife/husband was passed away, they don't want to marry another person and get birth.

Coming to the respondents' partner fertility desire, out of those who have fertility desire majority 85 (73.28\%) of respondents partner's wanted to have child. The study also revealed that, it was significantly associated with the need to have more children. Respondents whose husbands/wives/partners don't want to have child, had significantly lower fertility desire as compared to those respondents whose partners need more child, with $\mathrm{p}$ value 0.00001 . Once again this finding is supported by the qualitative finding that most respondents who wanted to have child explained that their partner has also fertility desire.

According to this study, there was no statistically significant association between fertility desire and knowledge of PMTCT, though it seems that patients who were not aware of PMTCT has lower fertility desire. Similarly, the study confirmed that, duration of HIV diagnosis, enrolment to ART care and duration of ART treatment have no significant association with fertility desire. Conversely, the qualitative finding revealed that, having knowledge about PMTCT has positive influence towards their fertility desire as compared to those who were not aware of PMTCT. Furthermore, respondents in the qualitative study explained that, starting ART treatment improves their health status, thus their fertility desire increases.

\section{Conclusionand Recommendation}

\section{Conclusion}

The most important factors identified asdeterminenat of fertility desire were marital relationship, partner fertility desire and respondents number of alive children. Findings from the analysis reveal that respondents with non married partner were four times more likely to have children in the future which is somewhat different our anticipation prior to analysis. Perhaps this is due the fact that those had not married partner want to have child/children as result of their partner relationship. Another important finding of this study is that the respondents who have less two children and whose partner desired to have fertility they tend to have fertility. In general, the result of this study revealed that a high number of HIV positive men and women desired children and reproductive decisions in peoples living with HIV are not only affected by their HIV status but depends on different predictor factors. Those who desire fertility are having no children or have less number of children, married or in relationship and have partners who also desire children.

\section{Recommendation}

- The concerned body (Ministry of Health including NGO's) 
should expand PMTCT service in all health centers including private sectors

- Further study should be conducted in large scale at regional or national(country) level

- Regular provision of on job training for all health workers to introduce them with new treatment modalities and to maximize their awareness about PMTCT.

- Since, data indicated that $83 \%$ knew PMTCT but only $59 \%$ knew that medication provided for PMTCT reduce the transmissionhigh number patients were not aware of PMTCT service, the concerned body including the health facilities should conduct advocacy and sensitization about PMTCT to all patients who visited the health center especially at $\mathrm{MCH}$ and ART clinics.

\section{References}

1. Almaz Hadgu (2011) Magnitude and factors affecting fertility Desire among women living with HIV in Addis Ababa City Administration, Ethiopia EPHA

2. UNAIDS (2010) outlook report.

3. Kakaire O1, Osinde MO, Kaye DK (2010) Factors that predict fertility desires for people living with HIV infection at a support and treatment centre in Kabale, Uganda. Reprod Health 7: 27

4. King R, Khana K, Nakayiwa S, Katuntu D, Homsy J, et al. (2011) Pregnancy comes accidentally - like it did with me': reproductive decisions among women on ART and their partners in rural Uganda. BMC Public Health 11:530.
5. Akinyemi JO, Awolude OA, Adewole IF, Kanki PJ (2010) Condom use among antiretroviral therapy patients in Ibadan, Nigeria. $\mathrm{J}$ Infect DevCtries 4: 495-502.

6. MenberuGetachew, FessehayeAlemseged, MulumebetAbera, AmareDeribew (2008) Factors affecting fertility decisions of married men and women living with HIV in South Wollo Zone, Northeast Ethiopia. Ethiop J Health Dev 24: 214-220.

7. UNAIDS (2006) AIDS epidemics update. Geneva.

8. Harvard School of Public Health Boston, MA (2010) The Pregnancy Intentions of HIV-Positive Women: Forwarding the Research Agenda. Conference Report 17-19, March 2010.

9. Myer L, Morroni C, Rebe K (2007) Prevalence and determinants of fertility intentions of HIV-infected women and men receiving antiretroviral therapy in South Africa. AIDS Patient Care STDS 21: 278-285.

10. FMOH (2003) Annual performance Report EFY 2003.

11. MOH- FHAPCO, FHAPCO.

12. TameneW,Fantahun M (2007) Fertility desire and family planning demand among HIV positive men and women in follow up care in Addis Ababa antiretroviral treatment in Addis Abba Ethiopia, Africa journal of AIDS 6:5.

13. Loutfy MR, Hart TA, Mohammed SS, Su D, Ralph ED, et al. (2009) Fertility desires and intentions of HIV-positive women of reproductive age in Ontario, Canada: a cross-sectional study. PLoS One 4: e7925.

14. Beyeza-Kashesya J, Ekstrom AM, Kaharuza F, Mirembe F, Neema S, et al (2010) My partner wants a child. A cross-sectional study of the determinants of the desire for children among mutually disclosed sero-discordant couples receiving care in Uganda. BMC Public Health 10: 247. 